\title{
Mathematics education: Building mathematical identities
}

Cite as: AIP Conference Proceedings 2215, 060006 (2020); https://doi.org/10.1063/5.0000581 Published Online: 01 April 2020

\section{Peter Grootenboer}

\section{ARTICLES YOU MAY BE INTERESTED IN}

Application of cooperative learning type teams games tournament (TGT) to increase the student's activity

AIP Conference Proceedings 2215, 060010 (2020); https://doi.org/10.1063/5.0000522

Reflective thinking in solving of open-ended problems in plane figure for seventh graders AIP Conference Proceedings 2215, 060009 (2020); https://doi.org/10.1063/5.0000652

Intrinsic cognitive load of students in solving problems linear program

AIP Conference Proceedings 2215, 060011 (2020); https://doi.org/10.1063/5.0000611

\section{Lock-in Amplifiers up to $600 \mathrm{MHz}$

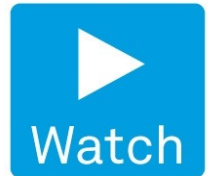

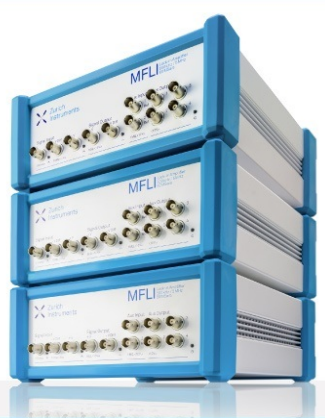




\title{
Mathematics Education: Building Mathematical Identities
}

\author{
Peter Grootenboer ${ }^{1, a)}$ \\ ${ }^{I}$ Griffith Institute for Educational Research, Griffith University \\ Gold Coast, Queensland, Australia \\ a)Corresponding author: p.grootenboer@griffith.edu.au
}

\begin{abstract}
For many years and across most of the world, mathematics has been seen as an unpopular and disliked subject, and many students have discontinued with mathematics as soon as they can. Furthermore, mathematics is often seen as difficult and disconnected from the 'real world', and so people perceive it as dull and boring, and irrelevant for them. Despite many years of research and investigation, this untenable situation does not seem to be improving. Therefore, in this paper the argument is that there needs to be new approaches to mathematics education and mathematics education research. Specifically, there is a pressing need to understanding mathematics more broadly than just a cognitive practice, and mathematics education as developing mathematical identities - head, heart and hand. This requires a more nuanced and personal understanding and appreciation of mathematics, and a more overt focus on the affect dimension of doing and learning mathematics. Research and development to this end needs to be more creative and flexible - it is already clear what the problem is, and so now proactive ways to ameliorate it in local contexts in necessary. Some ideas for this are discussed to conclude the paper.
\end{abstract}

\section{INTRODUCTION}

For over 60 years researchers and educators have investigated learners' affective responses to mathematics their beliefs about mathematics, attitudes towards mathematics, and emotional responses to learning and doing mathematics. In general, there has been persistent and consistent findings across different countries and in different eras, and these indicate that mathematics is difficult to learn and understand, that it is broadly disliked and to avoided wherever possible, and that it has little use in 'real life'. Despite some orchestrated efforts over the years to ameliorate and improve this situation, it seems that it has not really improved, and these negative views are pervasive amongst school students and adults alike. This has significant implications for individuals and society, particularly as mathematical skills and understandings are becoming increasingly important in modern life. Currently, for example, in Australia we are some 20000 mathematics graduates short every year to meet the needs of the society at large (e.g., industry, education, and business), and so there may be a looming crisis related to national mathematical capacity, and particularly in female participation [1]. With this in mind, it is perhaps time to reconsider approaches to mathematics education and mathematics education research, and here the suggestion is to consider focusing on mathematical identities.

\section{MATHEMATICS: HEAD, HAND, AND HEART}

It is a common conception that mathematics is a practice that is largely a cognitive in nature, and involves some particular skills and knowledge that are fixed and unchanging, but that is largely devoid of emotions or interest. It is interesting then, that mathematicians will describe their practices with words like 'beauty' and 'joy', and many (most) members of the general public will use descriptions like 'boring', 'dull' and 'hatred' [2]. Clearly mathematics involves more than just 'cold knowledge' and 'inert facts'. Therefore, here the idea of mathematical identities is

The 3rd International Conference on Mathematics and Sciences Education (ICoMSE) 2019

AIP Conf. Proc. 2215, 060006-1-060006-4; https://doi.org/10.1063/5.0000581

Published by AIP Publishing. 978-0-7354-1968-1/\$30.00 
proposed as an alternate way to consider mathematics and mathematics learning. Grootenboer and Marshman [3] stated that;

"the power of identity as a concept is that it can bring together a range of aspects that are fundamental to understanding mathematics education. Identity is a unifying idea that brings together multiple and interrelated dimensions that include beliefs, values, attitudes, emotions, dispositions, cognition, abilities, skills and life histories. While each of these aspects have been considered independently in many studies in mathematics education, the more comprehensive and holistic nature of identity captures the multi-dimensionality and complexity of mathematics teaching and learning."

This can be seen as a head, heart and hand approach [4], where mathematics and mathematics learning involves a cognitive component and specific knowledge (head), some particular skills and activities (hand), and affective engagement (heart). It seems that historically mathematics has been seen to involve mostly the head, and some work with the hand, but the heart dimension has been ignored, and this is a reason we face the current crisis of lack of mathematical participation and engagement. Furthermore, it has diminished the richness of the mathematical endeavor which is affective and emotional in nature. That said, it is important to note that a focus on mathematical identities does not diminish the importance of mathematical skills and knowledge, but rather it encompasses them alongside other important dimensions such as attitudes, beliefs, emotions and dispositions. Moreover, because the various dimensions are complexly inter-related, a focus on the identity means they can be considered simultaneously.

\section{Mathematics as an Affective Practice}

In 1997 Burton's research with research mathematicians found that their practices were largely collaborative, and the benefits for collaborating were practical (e.g., sharing the work), improved quality (e.g., greater range of ideas on problems), educational (e.g., learning from one another) and emotional (e.g., feeling less isolated). Interestingly, this seems to be at odds with how mathematics is experienced by learners, and hence the public perception of mathematics as a lonely activity done in isolation. Similarly, she also found that mathematicians have emotional, aesthetic and personal responses to mathematics; “... although knowing when you know is extremely important, you have to live with uncertainty. You gain pleasure and satisfaction from the feelings that are associated with knowing. These feelings are exceptionally important since, often despite being unsure about the best path to take to reach your objective, because of your feelings you remain convinced that a path is there. ... This is particularly poignant in the light of the picture painted of mathematics as being emotion-free" [5].

The mathematicians highlighted the joy and excitement of mathematical discovery, and they also used terms like "wonder", "beauty" and "delight" to describe their work, adding that these personal responses provided motivation and fuelled their love and commitment to mathematics. Mathematical philosophers Davis and Hersh [6] lamented that "blindness to the aesthetic element in mathematics is widespread and can account for the feeling that mathematics is dry as dust, as exciting as a telephone book ...". Finally, Burton also highlighted that the mathematicians actively sought rich connections, both between different branches of mathematics and to other disciplines [5].

What is striking here is the apparent distinction between the practices and identities of mathematicians, and the mathematical experiences of leaners at almost all other levels from preschool to undergraduate degrees. Indeed, this leads to questions about how 'mathematical' is the mathematics education provided for students? To this end, Burton asserted that "we have a responsibility to make the learning of mathematics more akin to how mathematicians learn and to be less obsessed with the necessity to teach 'the basics' in the absence of any student's need to know" [5]. Even at the most rudimental level, this would require mathematics education to have allied overt attention paid to the emotional, aesthetic and intuitive dimensions of the subject.

\section{MATHEMATICS EDUCATION AS DEVELOPING MATHEMATICAL IDENTITIES}

So with the preceding discussion in mind, an argument is made for considering mathematics education as being concerned with developing students' mathematical identities. It is important to note that the concept of 'identity' is complex and contested, but this debate will be largely ignored here as we take the term to mean "how people label and understand themselves". To develop mathematical identities, there is a need for learners to engage in authentic mathematics practices - head, heart and hand. This does not diminish the focus on the importance of mathematical knowledge, rather, it sees mathematics education as a way of enabling students to 'go on' mathematically, and to be 
empowered to practice mathematics in a range of contexts. Grootenboer and Marshman [3] noted that "students with healthy mathematical identities usually achieve better results in mathematics courses, will engage more wholeheartedly in their mathematical learning, are more likely to continue with their studies in mathematics, and will more readily participate in mathematical experiences." Here three factors are discussed that central to the development of strong mathematical identities: (1) the teacher; (2) the curriculum; and, (3) pedagogy that overtly considers affect.

First, it is important to note that the key factor in students' developing mathematical identities is the teacher. In the classroom, the teacher is not the provider of mathematical knowledge and instruction - they are also the 'face' of the discipline and the representatives of the mathematics community. Indeed, research has shown that when many students dislike and disengage from mathematics, the reasons that they give are not so much about mathematics but often about their mathematics teachers who are seen as cruel, cold and disinterested [7]. So, for teachers to support learners to develop mathematical identities, they must have a strong mathematical identity themselves. Often mathematics teachers purport to have a strong affiliation with mathematics, but in their lives outside their professional pedagogical work they rarely engage in mathematical practices [8]. Furthermore, they must see their pedagogical work as invitational, so students feel welcome and confident to engage themselves with mathematical practices.

Second, the nature of the experiences that constitute the curriculum in the mathematics classroom need to be authentically mathematical, and, responsive to the needs and interests of the learners. As noted previously, the mathematical experiences of the classroom seem to be qualitatively different from the practices of mathematicians, and so for many students they never really get to experience mathematics as it is practiced and understood by those in the community of practice. Significantly then, many have rejected mathematics because they have only experienced it in forms that are distant and somewhat foreign to the true mathematical endeavor. Therefore, it is important to consider the nature of mathematics and the practices of professional mathematicians in developing mathematics education [9]. Of note, Boaler [10] found after studying many mathematics classrooms in the UK, "that the mathematical epistemology that underpinned the teacher's pedagogy significantly influenced the mathematical identity developed by the students". While the nature of mathematics is a contested notion [6], it appears that it involves cognitive, physical and emotional labor, it focuses on problem solving and is usually collaborative and about finding connections [5].

Finally and relatedly given the historical practices of mathematics teaching, it is important that pedagogy overtly considers the affective dimension of learning. This does not mean trying to make mathematics 'fun' in a frivolous sense, but rather it involves first presenting mathematics as an exciting and fascinating field, and second, acknowledging the students emotional labor as they engage with and learn mathematical concepts and practices. Sometimes, even amongst the mathematics education community, there is an acceptance that mathematics is actually quite dull, and this is perhaps fueled by the impoverished versions of mathematics that can inhabit the curriculum. But this is not necessarily the case, and there are many aspects of mathematics that can have broad appeal and interest, including topics such as the ubiquitous Fibonacci Sequence and cryptography, to name but a couple. Of course, critical here is to find mathematical concepts and ideas, and their applications, that are interest to the learners at hand, and these will always be site-based and particular to each community. Relatedly, engaging students also involves caring for their emotions and attitudes and they learn mathematical concepts. There is no doubt that at times all students will need to struggle to learn new things, and so it is important at these times that teachers acknowledge and support the student's consternation and effort, so they are enabled to press through, and not give up and conclude that they are "just not good at maths" or that "they don't have a maths brain".

\section{CONCLUSION}

It is already clear that across many countries and contexts, and over many years, that many students are developing unhealthy and debilitating mathematical identities, and this can have a detrimental effect on their life opportunities and choices. Ironically, they are developing these poor views of mathematics, and themselves as practitioners of mathematics, in the very place where you would hope and imagine that they would grow strong and positive mathematical identities - in the mathematics classroom. This means that in places where mathematics is taught and learned, it is no longer good enough to just present clear accounts of mathematical concepts and worked solutions to seemingly meaningless problems. Something has to change otherwise the same untenable situation will continue to deteriorate. 
The mathematics classroom is made up of many interacting and complex dimensions, but the three significant aspects are the student, the teacher (and classroom community), and the discipline of mathematics (see Fig. 1).

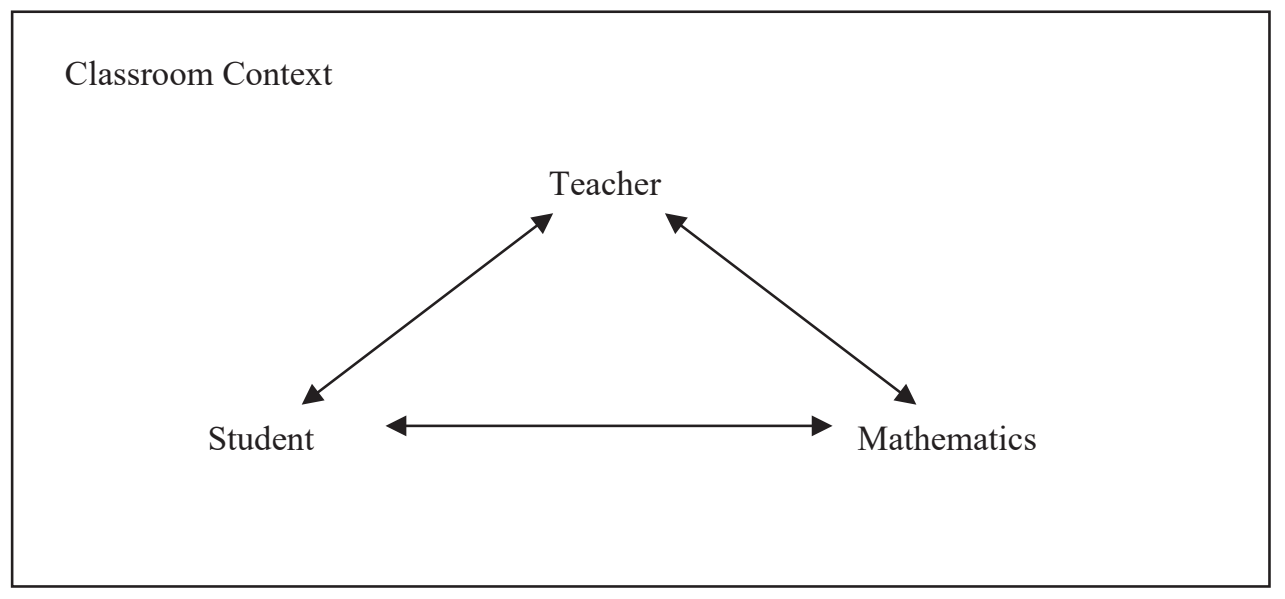

FIGURE 1. The learning milieu of the mathematics classroom [9]

Of course, it is more complex than this, but critically the key purpose here is for the teacher to facilitate the relationship between mathematics and the students (i.e., develop their mathematical identities). Indeed, what will remain once the year is finished is the student-mathematics connection, and therefore, this cannot be dependent on the teacher's ongoing presence or input. This means that an effective mathematics education program will involve, over the teaching period, having the students operate increasingly as confident, independent and capable mathematicians.

\section{ACKNOWLEDGMENTS}

The author acknowledges the support and advice provided by colleagues Associate Professor Catherine Attard, Associate Professor Christine Edwards-Groves, and Dr Kevin Larkin in preparing this paper.

\section{REFERENCES}

1. I. Koch (Ed.), Gender Report 2019: Mathematics and Gender: Are Attitudes and Anxieties Towards Mathematics Changing (Australian Mathematical Sciences Institute, Melbourne, 2019).

2. L. Burton, Educational Studies in Mathematics 37, 121-143 (1999).

3. P. Grootenboer and M. Marshman, Mathematics, Affect and Learning: Middle School Students' Beliefs and Attitudes About Mathematics Education (Springer, Singapore, 2017).

4. T. Sergiovanni, "Towards a Theory of Supervisory Practice: Integrating Scientific, Clinical, and Artistic Views," in Supervision in Teaching, edited by T. Sergiovanni (Association for Supervision and Curriculum Development, Alexandria, VA, 1982), pp. 35-52.

5. L. Burton, British Educational Research Journal 27, 589-599. (2001).

6. P. J. Davis and R. Hersh, The mathematical experience (New York, Mariner, 1998).

7. P. Grootenboer, Culture and Society 21, 321-342 (2013).

8. J. Balantyne and P. Grootenboer, International Journal of Music Education 30, 368-381 (2013).

9. P. Grootenboerand R. Zevenbergen, "Identity and mathematics: Towards a theory of agency in coming to learn mathematics" in Mathematics: Essential research, essential practice 2007, Conference Proceedings 30, edited by J. Watson and K. Beswick (Mathematics Education Research Group of Australasia, Tasmania, 2007), pp. 335-344.

10. J. Boaler, "Studying and capturing the case of the dance of agency," in Proceedings of the 27th annual conference, edited by N. Pateman, B. Dougherty and J. Zillox (International Group of Psychology of Mathematics Education, Hawaii, 2003), pp. 3-16. 